\title{
Expression of the gene for ribosomal protein L1 in Xenopus embryos: alteration of gene dosage by microinjection
}

\author{
Paola Pierandrei-Amaldi, ${ }^{1}$ Irene Bozzoni, ${ }^{2}$ and Beatrice Cardinali ${ }^{1}$ \\ ${ }^{1}$ Istituto di Biologia Cellulare, C.N.R., via Romaghosi 18A, 00196 Roma $^{2}$ Dipartimento di Genetica e Biologia Molecolare, I \\ Universita' di Roma La Sapienza, 00185 Roma, Italy
}

\begin{abstract}
Cloned gene for Xenopus ribosomal protein L1 was injected into fertilized eggs, and its expression was analyzed during the period of embryo development when the mRNAs produced by the endogenous ribosomal protein genes are still silent due to a translational control. The injected genes replicated extensively, and a 10-fold excess of $L 1$ mature transcript accumulated in the embryo. This was accompanied by a small amount of incompletely processed L1 RNA that still contained one out of nine introns, a molecule never observed in normal conditions. The excess mature L1 mRNA was distributed between polysomes and messenger ribonucleoproteins (mRNPs) in the same relative proportion observed in control embryos of the same stage. Therefore, more L1 mRNA was loaded onto polysomes and caused the appearance of L1 protein when this was not yet detectable in control embryos. The results suggest a relationship between the excess amount of $L 1$ protein and the alteration in processing of its transcripts.
\end{abstract}

[Key Words: Xenopus laevis; ribosomal proteins; regulation; gene injection]

Received August 12, 1987; revised version accepted November 10, 1987.

In previous studies we analyzed the expression of ribosomal protein (r-protein) genes at various regulatory levels during the development of normal Xenopus embryos and of anucleolate mutants homozygous for a deletion of the rRNA gene cluster. The general view outlined by our studies implies that at least two types of control mechanisms are involved in the regulation of $r$ protein synthesis in the Xenopus system. Control at the level of translation establishes what fraction of $r$-protein mRNA (rp-mRNA) must be loaded onto polysomes, and this control seems to respond to the need for new ribosomes, as occurs in early embryogenesis when the rpmRNA is kept silent on messenger ribonucleoproteins (mRNPs) before being translated. Control at the posttranscriptional level regulates the stability of the r-protein transcripts and seems to be related to an overproduction of $r$-proteins relative to the amount needed for ribosome assembly (Pierandrei-Amaldi et al. 1982, $1985 a)$.

At present we have no positive clues about the mechanisms responsible for this kind of translational control, which is also reported in other eukaryotic systems (Geyer et al. 1982, Kay and Jacobs-Lorena 1985; Schimdt et al. 1985); although we have ruled out the possibility that it is of an autogenous nature (Pierandrei-Amaldi et al. 1985a,b). This is at variance with prokaryotes, in which r-proteins, if synthesized in excess, specifically block further translation of their own mRNA (Nomura et al. 1984). On the other hand, at least for r-protein L1, we have some indications on the mechanism that presides over the post-transcriptional control. These come from experiments in which the gene dosage for $r$-protein Ll has been altered by injection of an excess of the corresponding cloned gene into the germinal vescicles of Xenopus oocytes (Bozzoni et al. 1984). The chromosomal genes are already engaged in an active synthesis of the $r$-proteins necessary for the ribosomal accumulation typical of oogenesis; upon injection, they actively transcribe the excess $L 1$ genes, but do not produce the corresponding mature mRNA while accumulating a large amount of a specific precursor RNA which still retains two out of nine intron sequences (Bozzoni et al. 1984). We have also found that this specific block of processing is partially prevented by coinjecting, together with L1 genes, antibodies raised against $\mathrm{L} 1$ protein (PierandreiAmaldi et al. 1987). These results suggest the possibility that an autogenous regulation, operated directly or indirectly by the final product (that is, $\mathrm{L} 1$ protein), controls the amount of mature mRNA by blocking a specific step of its transcript processing. Thus the oocyte, which is 
synthesizing r-proteins in the proper amount for its ribosome accumulation, would prevent an excess production of the $\mathrm{L} 1$ protein component of the ribosome.

If this interpretation is correct, one would expect different behavior when extra copies of cloned L1 genes are injected into fertilized eggs and their expression is analyzed during the first part of embryogenesis. In fact in this period, schematically illustrated in Figure 1, rpmRNA is synthesized and accumulated by the normal embryo after the midblastula transition, but it is scarcely translated up to stage 26; r-proteins start to be actively synthesized only at later stages, when $70-80 \%$ of rp-mRNA becomes recruited on polysomes (Pierandrei-Amaldi et al. 1982; Baum and Wormington 1985). Therefore, at variance with the oocyte, early embryo cells are devoid of free r-proteins. In this case one can predict that the excess transcripts produced upon Ll gene injection should be processed normally.

With this in mind we have injected cloned Ll genes into fertilized eggs and analyzed their expression during the "pretranslational period of rp-mRNA." To prevent impairing of the normal regulatory processes involved in the production of $\mathrm{r}$-protein $\mathrm{L} 1$, we preferred not to modify the gene to be injected. In this way the transcripts cannot be distinguished from the endogenous ones, but this is not relevant in this study where an overproduction of normal Ll transcripts was desirable.

\section{Results}

\section{Fate of injected DNA}

The isolation and characterization of a cloned Xenopus genomic fragment containing the gene for $r$-protein L1 has been described (Bozzoni et al. 1982; Loreni et al. 1985). pLl, a subclone in pBR322 carrying an insert of 12 $\mathrm{kb}$ (Bozzoni et al. 1984), was used for microinjection (Fig. 1). Supercoiled pLI DNA was injected into Xenopus fertilized eggs in amounts ranging from 50 to $400 \mathrm{pg}$ per egg, corresponding to the order of a few million gene copies. Some eggs were injected only with buffer and used as controls. The amount of DNA injected was crucial for the viability of the embryos. In fact $300 \mathrm{pg}$ or more was lethal and embryos did not pass gastrulation; with lower amounts of DNA, viability progressively increased. It was found that embryos injected with 50 or $100 \mathrm{pg}$ are highly viable but often replicate the injected DNA poorly, whereas a combination of good replication efficiency and viability was obtained using $200 \mathrm{pg}$ of $\mathrm{pL} 1$ DNA, as also observed by other authors (for instance see Rusconi and Schaffner 1981). Thus, 200 pg was the amount of DNA routinely used for injections. It must be pointed out that a certain degreee of variability in the response to the injected DNA was observed among different batches of eggs. Figure 2 shows an example of the replication pattern of the injected Ll DNA at different stages of development. Total nucleic acid was extracted from buffer and DNA-injected embryos of various developmental stages; aliquots corresponding to one embryo were analyzed by Southern blotting and hybridized to L 1 probe. To allow better quantitation, the extracted DNA

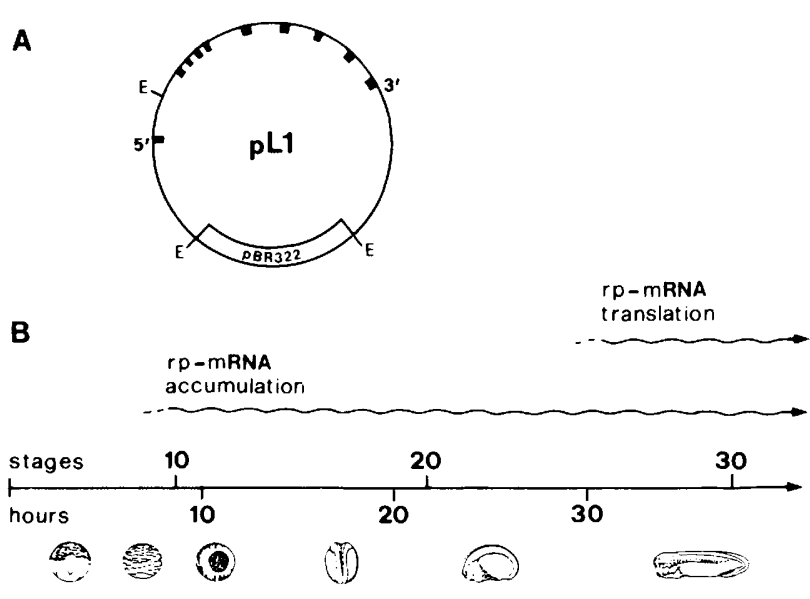

Figure 1. $(A)$ Schematic representation of the recombinant plasmid $\mathrm{pLl}$, used for microinjections. A 12-kb Xenopus genomic fragment containing the $\mathrm{L} 1$ gene is inserted in the EcoRI site of pBR322 (Bozzoni et al. 1982; Loreni et al. 1985). The 5' and $3^{\prime}$ ends of the $\mathrm{L} 1$ gene are indicated; the 10 exons are represented by black boxes. (E) EcoRI restriction site. (B) Timing of $r$-protein gene expression during Xenopus development (Pierandrei-Amaldi et al. 1982). rp-mRNA starts to be accumulated around stage 10 , but is underutilized until stage 26 . The experiments described in this paper have been carried out between these two stages. Embryo stages are according to Nieuwkoop and Faber (1956).

was digested with BamHI, which cleaves the injected DNA at two sites, one in the vector and the other within the gene (Fig. 2A). The endogenous chromosomal L1 gene also gives two bands, but of different mobilities, visible in Figure $2 \mathrm{~A}$ in lanes $\mathrm{d}$ of the first and second sets of samples; in lane $\mathrm{d}$ of the third set of samples (200 pg) they are covered by the large amount of replicated DNA. In some experiments, such as the one shown in Figure 2, the amount of DNA increased up to stage 35 ; in other experiments the maximum was reached around gastrulation (stage 10), but persisted in the following stages. The extent of L1 DNA increase with respect to the DNA injected varied between $10-$ and 50 -fold, as determined by densitometric analysis. However, for the purposes of this study the relevant point is the increment of the number of Ll gene copies with respect to the endogenous one. The difference between the amount of the endogenous L1 gene and the amplified DNA can be appreciated by comparing the control and the injected embryos at stage 35 (lanes $\mathrm{d}$ in Fig. 2). In fact the injected embryos contain several tens of excess copies, as compared with controls, which at this stage only have enough cells (about $3 \times 10^{5}$ ) to make a single copy gene just visible (Fig. 2A, first panel, lane d). Undigested DNA from the embryos injected with $200 \mathrm{pg}$ was also analyzed to show the conformational state of the amplified copies (Fig. 2B). As previously described for other injected genes (Rusconi and Schaffner 1981; Andres et al. 1984; Bendig and Williams 1984; Etkin et al. 1984), the supercoiled molecules are relaxed immediately after injection. Later some of the amplified sequences appear as supercoiled monomers, and most of them appear as 


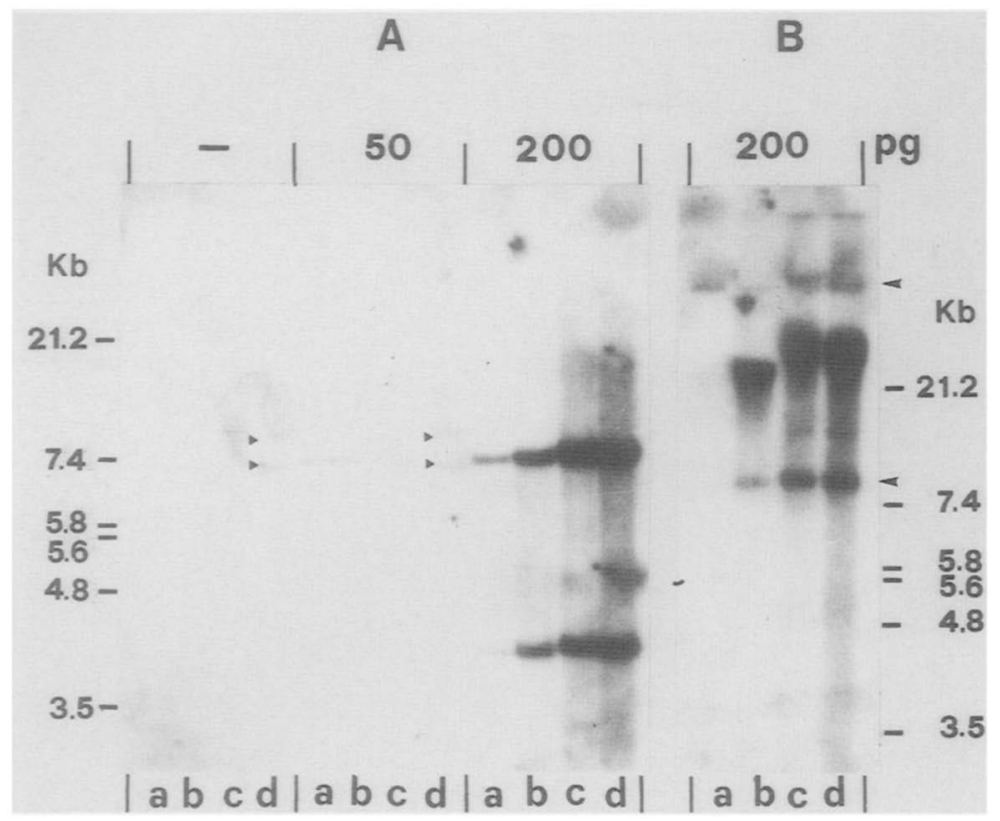

Figure 2. Replication in developing embryos of L1 genes injected into fertilized eggs. At various stages DNA was extracted, analyzed by Southern blotting, and hybridized to an L1 probe. Each lane was loaded with the DNA equivalent to one embryo, digested with $B a m H I|A|$, or undigested $(B)$. The amount of DNA injected is indicated at the top and the stages are analyzed at the bottom: before first cleavage (lanes $a$ ); stages 12 , 31 , and 35 (lanes $b, c$, and $d$ respectively). In $A$ arrowheads point to bands corresponding to the endogenous gene; in $B$ arrowheads indicate the position of relaxed (upper) and supercoiled (lower) plasmid. Molecular weight markers $(\lambda$ DNA digested with EcoRI) are indicated in kilobases. high-molecular-weight forms that have the same mobility as the endogenous bulk genomic DNA (not shown). The complete conversion of these high-molecular-weight forms into the two bands expected after digestion with BamHI (Fig. 2A) indicates that the plasmid is present as concatenates up to the tailbud stage. We have not investigated whether they remain episomal or integrated into the host DNA.

\section{Transcription and accumulation of L1 RNA in injected embryo}

Once we had established that a large amount of template was produced after injection of the L1 gene, we checked if it was transcribed and how its transcripts were utilized. Poly $(\mathrm{A})^{+}$RNA from buffer and DNA-injected embryos was analyzed by Northern blotting and hybridized to $L 1$ probe. We observed that up to stages $7-8$, although there was a considerable increase of the injected DNA, no Ll transcripts were detectable, but around stage 10 an excess amount of $\mathrm{Ll}$ transcript started to accumulate in injected embyros as compared with controls (not shown). No hybridization was found in poly(A)- RNA.

We have focused our attention in particular on the developmental period that precedes stage 26 , when the rpmRNA is poorly translated. Figure $3 \mathrm{~A}$ shows an example of $\mathrm{Ll}$ transcript accumulation at stages 14 and 20 in embryos injected with L1 DNA. The amount of transcript is 5- to 10-fold higher than in buffer-injected embryos as determined by densitometric analysis. A correlation between transcript accumulation and DNA increase was constantly observed. Most of the Ll transcript has the same mobility as mature L1 RNA of control, but a slower migrating band is observed in the RNA from injected embryos. This band has never been observed in RNA from controls of the same stage or of later stages even after overexposure of the autoradiographs, and it is not merely related to the higher signal given by the RNA from injected embryos (Fig. 3B, lane 2 as compared with lane 1). In fact in lanes overloaded with RNA from normal embryos and oocytes, which gives a very high signal, the slower band is absolutely absent (lanes 4 and 5). The increase of transcript is specific for $\mathrm{L} 1$ sequences; in fact if the same filter was hybridized a second time to a probe for the r-protein L14, there was no difference between control and injected embryos (Fig. 3C).

The presence of heavier L1 transcripts after injection of the L1 gene was formerly observed in oocytes, and it was demonstrated that they still retained either the second and third introns or only the third (Bozzoni et al. 1984; Caffarelli et al. 1987). To establish if we were dealing with the same premature L1 RNA, we compared by Northern blotting and $\mathrm{Sl}$ analysis the RNA from injected oocytes and embryos. Figure 4 shows a Northern blot analysis of poly(A) ${ }^{+}$RNA from embryos injected with the Ll gene (lane a) run in parallel with similarly treated oocytes (lane b), which are known to accumulate Ll transcripts still retaining the second and third introns. It appears that in the embryo the premature transcripts migrate somewhat faster than the corresponding one in the oocyte. To define the structure of such RNA species precisely, we compared the RNAs from L1-injected embryos and oocytes by S1 analysis (Fig. 5). The probe utilized was a 813 -bp-longXbaI-PvuII fragment that covers $633 \mathrm{bp}$ of the Ll gene (from the $\mathrm{XbaI}$ site inside intron 3 to the PstI site inside exon 2). The remaining $180 \mathrm{bp}$ belong to the vector from which the probe utilized was a 813-bp-long XbaI-PvuII fragment in the $X b a I$ terminus to map the sequences upstream to this site, thus allowing the identification of transcripts that contain either intron 3 alone or introns 2 and 3 . From the figure it appears that the RNA from injected oocytes gives two bands of S1 protection: a 633-bp fragment corresponding to protection from the $\mathrm{XbaI}$ site to 


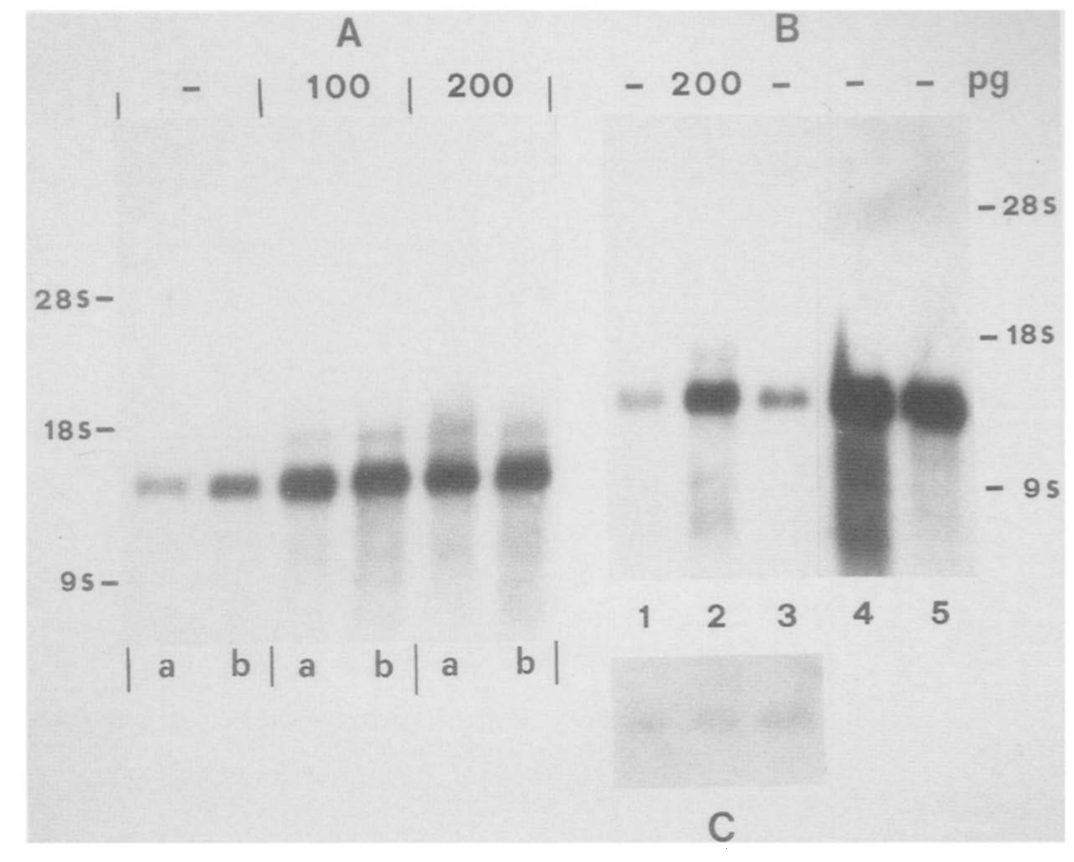

Figure 3. Accumulation of $\mathrm{L} 1$ transcripts in injected embryos. $(A)$ Poly $(A)+$ RNA was prepared from groups of embryos of two stages; the equivalent of two embryos was separated on Northern gels, blotted, and hybridized to an L1 probe. The amount of DNA injected is indicated at the top, and the stages are indicated at the bottom: stage 14 (lanes $a$ ) and stage 20 (lanes $b)$. (B) Poly $(A)^{+}$ RNA from two embryos of stage 20 injected with buffer (lane 1) and pLl (lane 2) is compared with RNA from the same number of buffer-injected embryos of stage 30 (lane 3), with RNA from 40 (20-fold) buffer-injected embryos of stage 20 (lane 4 , and $0.5 \mu \mathrm{g}$ of poly $(\mathrm{A})^{+}$RNA from uninjected Xenopus oocytes (lane 5$)$. (C) Lanes 1, 2, and 3 of the experiment shown in $(B)$ were rehybridized to a probe for L14.

the PstI site and a 323-bp fragment corresponding to protection from the $X b a I$ site to the $5^{\prime}$ border of exon 3 . These fragments correspond to the protection of precursors containing intron 3 or introns 2 and 3 . The RNA from L1-injected embryos contains mainly the precursor with intron 3; after a long exposure the precursor containing the two introns can also be visualized. This result demonstrates that the slower migrating band observed in Northern blots is indeed a precursor RNA containing at least intron 3 . A similar analysis, performed using a probe $3^{\prime}$-end-labeled in the BstEII site inside exon 2, covered the same region as the previous one and allowed the mapping from exon 2 downstream. This analysis showed that no precursors containing only intron 2 are present in oocytes or embryos (not shown). This finding indicates that intron 2 can still be spliced from the precursor RNA, though with lower efficiency with respect to the other introns, whereas the removal of intron 3 seems to be a major limiting step in the production of mature Ll RNA.

\section{Translation of the excess $L 1$ mRNA}

As previously mentioned, in early embryogenesis the rpmRNA is regulated by translational control (PierandreiAmaldi et al. 1982; Baum and Wormington 1985). Therefore it is of interest to know if the excess of mature L1 mRNA present in the injected embryos is used during this period. Embryos injected with buffer and DNA were labeled with $\left[{ }^{35} \mathrm{~S} \mid\right.$ methionine around stage 18 to see if $\mathrm{Ll}$ protein was synthesized before its time. Labeling was carried out for $45 \mathrm{~min}$, since it is known from previous experiments that unused $\mathbf{r}$-proteins are unstable and are degraded with a half-life of about $1 \mathrm{hr}$ (PierandreiAmaldi et al. 1985a). To reduce the effect of individual variability we analyzed groups of eight embryos, injected with either buffer or DNA. At the end of incubation with $\left.{ }^{35} S\right]$ methionine, each group was homogenized in conditions suitable to preserve nucleic acids and proteins and quickly divided into three parts, which were processed for analysis of DNA, RNA, and proteins (see Materials and methods). Thus, it was possible to know for each group of embryos the relationship among template, transcript, and protein product.

Proteins were acid-extracted, loaded on gels together with purified Xenopus r-proteins as internal standard, and analyzed by two-dimensional gel electrophoresis and fluorography. Figure 6B shows the typical pattern of proteins synthesized at stage 18 of normal development, when histones and some unidentified spots are constantly found, but r-proteins are not yet detectable. In the gel loaded with protein synthesized by embryos of

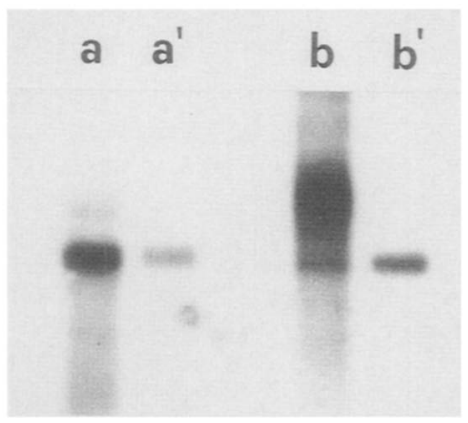

Figure 4. Comparison of transcripts produced by embryos and oocytes injected with the $\mathrm{Ll}$ gene. Poly $(\mathrm{A})^{+}$RNAs from stage 20 pLl-injected embryos (a), stage 20 buffer-injected embryos $\left(a^{\prime}\right)$, stage VI pLl-injected oocytes $(b)$, and stage VI buffer-injected oocytes $\left(b^{\prime}\right)$ were analyzed by Northern blot with an L1 probe. The gel was loaded with the RNA equivalent of two individuals. 


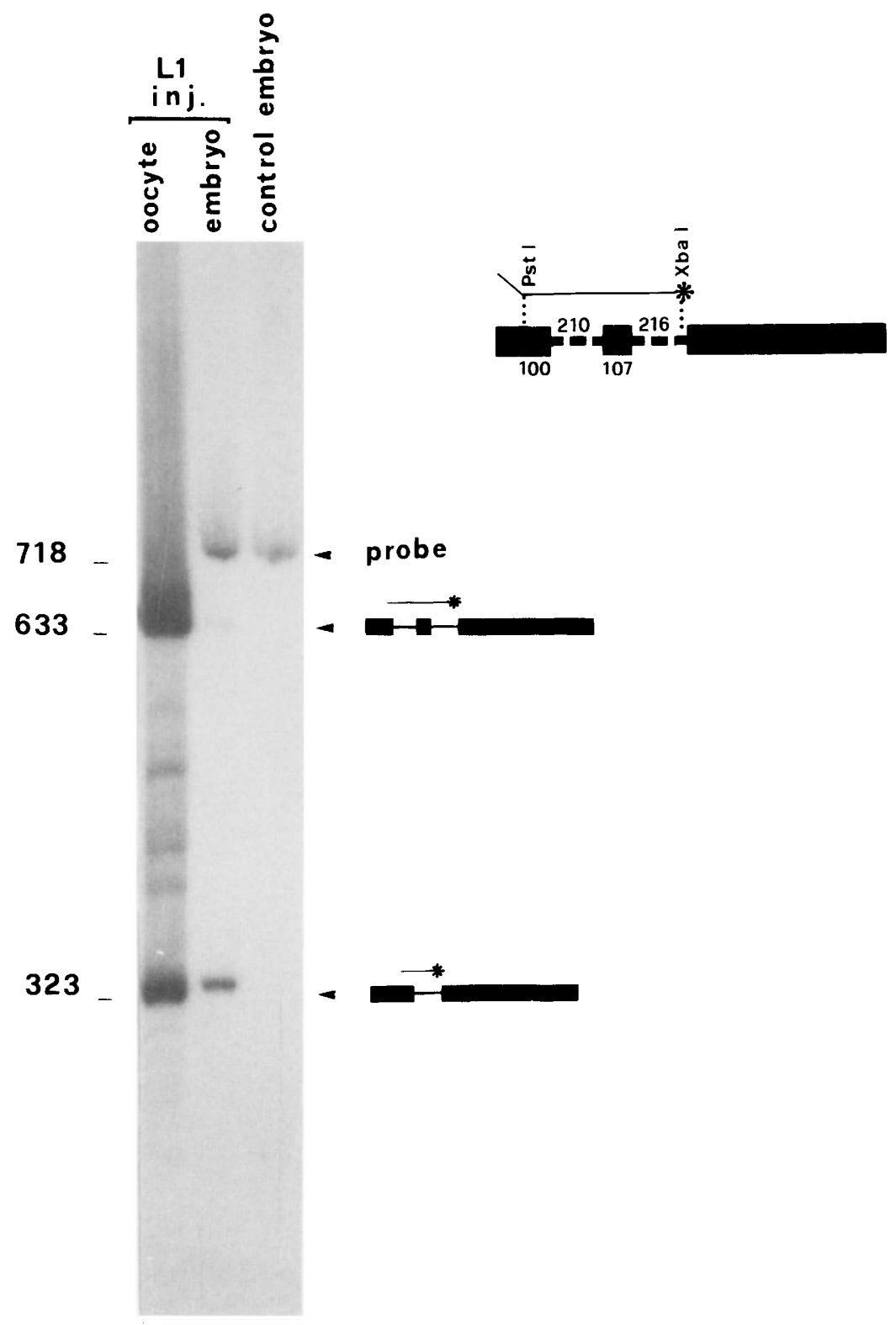

Figure 5. S1 analysis of RNA from embryos and oocytes injected with the Ll gene. The protected RNA from 10 embryos injected with buffer and pLl and from 10 oocytes injected with pLl is shown. (Upper right) The probe labeled at the $5^{\prime}$ end $\left({ }^{\circ}\right)$ and the precursor region which it recognizes (still containing introns 2 and 3); (below) the structure of the two precursor forms revealed by the Sl protection.

the same stage injected with LI DNA, the same pattern of control is observed except for the appearance of $\mathrm{Ll}$ protein (Fig. 6A). To show the position of r-proteins in this kind of gel, a later-stage pattern, when all r-proteins have started to be synthesized, is presented in Figure 6C (Pierandrei-Amaldi et al. 1982). Most of the faint spots present in this panel and absent in A and B are r-proteins as determined by comigration with stained internal standards in this gel optimized for basic proteins. We have checked that the RNA corresponding to the sample shown in Figure 6A contained a large amount of mature L1 transcript accompanied with the band corresponding to premature L1 RNA. A quantitation of the relative in- tensity of the autoradiographic signals was carried out by densitometric analysis of the fluorographs of this and other similar experiments. The intensity of the L1 spot was normalized toward other spots considered as standards. The increase in protein $\mathrm{L} 1$ in injected embryos was calculated to be 5- to 10 -fold over the controls that were overexposed to make the Ll spot barely visible.

Distribution of the excess L1 RNA between polysomes and $m R N P S$

Considering that the translational control of rp-mRNA observed in developing Xenopus embryos operates by 

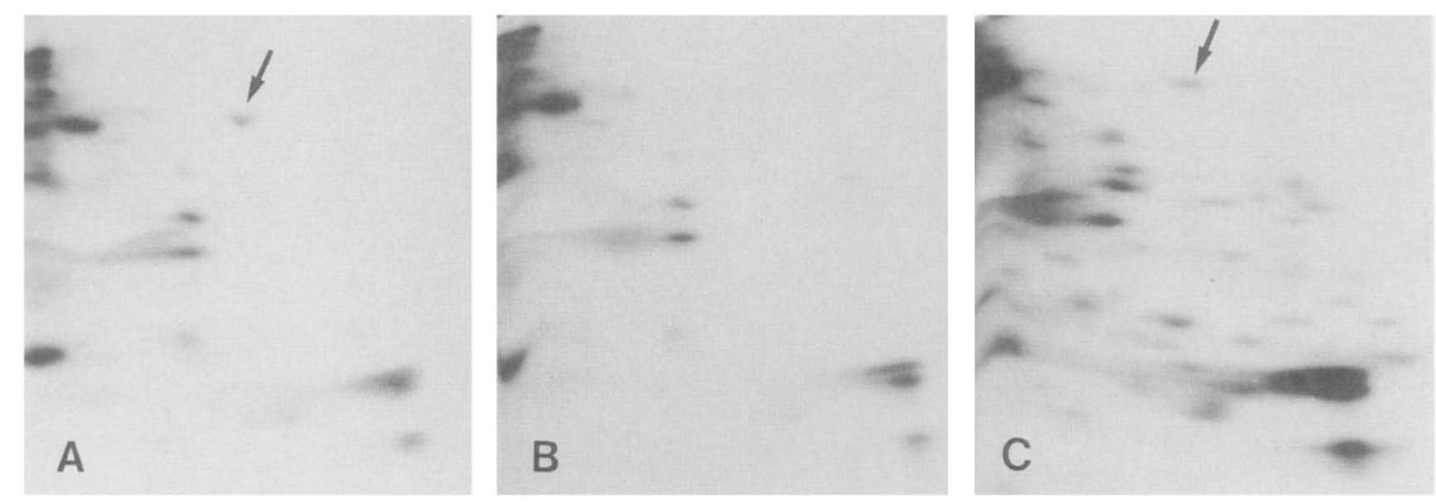

Figure 6. Fluorographs of acrylamide gels loaded with proteins synthesized by embryos injected with the Ll gene. Embryos injected with $\mathrm{pL} 1|A|$ and buffer $(B)$ were labeled at stage 18 with $\left[{ }^{35} \mathrm{~S}\right]$ methionine; proteins were extracted and the equivalent of three embryos was run on two-dimensional acrylamide gels together with purified Xenopus r-proteins and fluorographed. For comparison a pattern of proteins synthesized by older embryos (stage 28), when r-proteins become visible, is shown $(C)$. Arrows point to r-protein L1. Identification of labeled $\mathrm{Ll}$ and other r-proteins was determined by comigration with stained Xenopus r-proteins used as internal markers.

changing the distribution of this mRNA between polysomes and mRNPs, it was of interest to know how the excess of L1 RNA was distributed between the two cellular compartments of injected embryos. Groups of buffer- and DNA-injected embryos were collected around stage 18 when, as mentioned above, in normal embryogenesis the great part of rp-mRNA is on mRNPs. Nuclei were removed and the cytoplasmic extracts were separated on sucrose gradients: each gradient was loaded with material corresponding to 10 embryos. Gradient fractions were collected in polysomes and $\mathrm{mRNP}$ pools and the RNA extracted as described in Materials and methods. Poly $(\mathrm{A})^{+}$RNA was then analyzed by Northern blotting and hybridized to a probe for L1. (Purification of poly $(\mathrm{A})^{+}$RNA was necessary, since a certain amount of injected plasmid DNA could be present in the cytoplasm and disturb the analysis.) Figure 7 shows the Northern blot of poly $(\mathrm{A})^{+}$RNA from stage 18 polysome and mRNP fractions of buffer- $(A)$ and DNA-injected (B) embryos. It can be observed that $\mathrm{L} 1$ transcript is much higher in $\mathrm{B}$ than in $\mathrm{A}$; however, a densitometric analysis of the films of this and other similar experiments, carried out at stages 18 and 23, has shown that the relative amount of Ll mRNA localized on polysomes in injected embryos is approximately the same as in controls, namely around $10 \%$ at stage 18 and somewhat higher at stage 23 . We have observed that the L1 RNA migrates as a single band in all the cytoplasmic fractions, whereas the premature Ll RNA was found only in the nuclear fraction (not shown). The same filter was rehybridized to a probe for protein L14; there was no difference in the amount or distribution of L14 mRNA in control and injected embryos.

\section{Discussion}

Taking advantage of the peculiar expression pattern of r-protein genes in the early phase of Xenopus development, when rp-mRNAs are accumulated but underutilized for translation, we have increased the gene dosage for r-protein L1 to see how this alteration would interfere with the normal expression program of this gene. Injection of the cloned gene in fertilized eggs was a useful tool to achieve this.

We have shown here that the plasmid containing a Xenopus $12-\mathrm{kb}$ genomic fragment with the $\mathrm{Ll}$ gene is efficiently replicated and can persist in the embryo up to hatching (stage 35), apparently as high-molecular-weight concatenates. Increase of $\mathrm{L} 1$ gene as compared with control embryos was, after gastrulation, between 10- and 50 -fold as determined by densitometric analysis. Since the injected DNA replicated so much and persisted long enough for our purpose, we have not tried linearization of the plasmid which, for other DNAs, has been described to improve replication, persistence, and expression (Mohun et al. 1986; Wilson et al. 1986). Although in our case the DNA was not linearized, it is assumed that it is the high-molecular-weight form that produces ex-

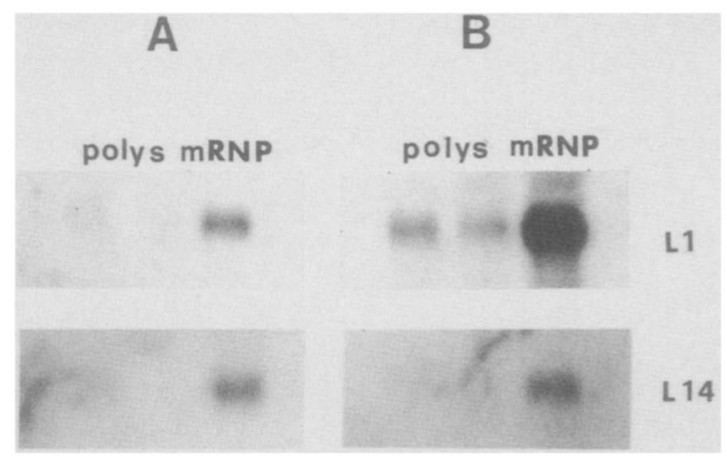

Figure 7. Distribution of $L 1 \mathrm{mRNA}$ on polysomes and mRNPs in buffer- and $\mathrm{pL} 1$-injected embryos. Cytoplasmic extracts from buffer- $(A)$ and pLl-injected $(B)$ embryos of stage 18 were fractionated on sucrose gradients. The regions corresponding to polysomes and mRNPs were pooled and the corresponding RNA was analyzed by Northern blot hybridization with L1 probe. As a control, the same filter was rehybridized to an L14 probe. 
pression, as indicated by these previous authors. Thus, different DNAs might show different behavior: in fact when we injected a circular plasmid carrying a gene for another r-protein we observed that it replicated less efficiently than $\mathrm{Ll}$, remained mostly supercoiled, and resulted in lower expression (P. Pierandrei-Amaldi et al. unpubl.). Moreover when a gene specifically expressed at gastrula was injected in supercoiled form, it was not significantly amplified and it was correctly transcribed in the embryo (Krieg and Melton 1985).

The large increase of Ll DNA is accompanied by a corresponding increase of the transcript. The excess Ll RNA starts accumulating around gastrulation, as in control embryos. In stages immediately following, namely in the period of time when in normal development the rp-mRNA is very poorly translated, the amount of L1 transcript was 5- to 10-fold higher than in controls. Most of the excess Ll transcript comigrates with mature Ll mRNA, and it is responsible for the early appearance of detectable $\mathrm{L} 1$ protein in the injected embryos. An interesting feature has been observed by analyzing the distribution of the excess L1 mRNA between polysomes and mRNPs in injected embryos and comparing it with the distribution of L1 mRNA in control embryos. It was found that this mRNA, although present in higher amount, has a relative distribution between the two compartments similar to controls, and typical of the developmental stage at least for the stages analyzed. This result provides an interesting clue about the mechanism involved in the translational regulation previously described for rp-mRNA in Xenopus development; namely, that the percent, rather than the amount, of rp-mRNA to be loaded onto polysomes is regulated. A similar result was obtained in Drosophila embryos injected with an r-protein gene ( $M$. Jacobs-Lorena, pers. comm.).

In injected embryos the described increase of mature L1 mRNA is accompanied by the appearance of a small amount (about 5-10\%) of larger Ll transcripts. These turned out to be premature forms of L1 RNA which still retained the third and sometimes also the second of the nine intron sequences, and are localized in the nucleus. These premature forms are evident exclusively in L1DNA-injected embryos, which have more copies of this gene and were never observed in physiological conditions. It is unlikely that the appearance of the premature form is due to an overloading of the splicing system, as the excess Ll transcripts are very few compared with total ones (endogenous mRNA for each r-protein is about $0.1 \%$ of total poly $(\mathrm{A}){ }^{+}$RNA). Moreover, except for introns 2 and 3, the other seven introns of Ll primary transcripts are processed normally. Furthermore, we have never observed any effect on the processing of the endogenous transcript for another r-protein (L14) in embryos injected with L1 genes.

Premature L1 RNA was first described in oocytes microinjected with the same L1 gene. Most Ll transcripts were not fully matured and retained the same introns; consequently no excess Ll protein was produced (Bozzoni et al. 1984). As an interpretation of that result it was postulated that in the oocyte, which is actively syn- thesizing r-proteins, L1 protein would prevent the production of excess amounts of itself by specifically blocking the maturation of the corresponding RNA. This block was in fact partially prevented by injection of antibodies against L1 (Pierandrei-Amaldi et al. 1987). The results described here indicate that, on the contrary, most of the excess L1 transcript goes through maturation in early embryogenesis, causing the early appearance of $\mathrm{L} 1$ protein. After examining the results of several experiments, we propose that the excess L1 transcript is allowed to mature normally as long as the system is devoid of free $\mathrm{Ll}$ protein. When a certain amount of the excess L1 mRNA is loaded on polysomes, a corresponding amount of $\mathrm{L} 1$ protein is produced, too early to be assembled in the nucleus with the other ribosomal components which are not yet available. This unused L1 protein would make the system somewhat aware of its excess synthesis and would determine a block in the processing of the $\mathrm{L} 1$ transcripts that probably will take the way of degradation. A comparable situation was previously observed in the anucleolate embryo, which begins to decrease the level of its rp-mRNA only when the r-proteins start to be actively synthesized, namely around stage 30 (Pierandrei-Amaldi et al. 1985a). In this case only the final effect of degradation appeared, whereas in the injected embryo it was possible to make evident the intermediate steps (unprocessed transcripts) because of the overloading of the system.

In conclusion, the results described above support our previous interpretation that the expression of the Ll gene is regulated at a post-transcriptional level by an autogenous mechanism that operates at a specific step of transcript maturation, thus controlling the stability of its RNA. An analogous mechanism of regulation for some r-proteins was reported in yeast (Team and Rosbash 1983; Dabeva et al. 1986). The precise role of the final product in this regulatory process is still under investigation.

The persistence of the injected Ll gene and its expression provide the possibility of further studies by injection of mutagenized genes to identify DNA sequences involved in regulation at the post-transcriptional and translational levels.

\section{Materials and methods \\ Injection of fertilized eggs and oocytes}

Artificially fertilized eggs, obtained from hormone-stimulated Xenopus laevis females and dejelled before fertilization, were placed on nylon nets in dechlorinated water and injected in the animal hemisphere within an hour with $10 \mathrm{nl}$ of buffer or DNA solution delivered by a glass needle connected with a mechanically driven microsyringe. The fertilization protocol was as described by Rusconi and Schaffner (1981). Developing embryos were incubated in dechlorinated water plus $150 \mu \mathrm{g} / \mathrm{ml}$ of penicillin and streptomycin at $20^{\circ} \mathrm{C}$. At the appropriate stage, $1 \mu \mathrm{Ci}$ of $\left[{ }^{35} \mathrm{~S}\right.$ ]methionine in $100 \mathrm{nl}$ (New England Nuclear, sp. act. 800 $\mathrm{Ci} / \mathrm{mmole}$ ) was microinjected into the dorsal part of the embryo, which is impermeable to amino acids. After labeling, embryos were collected in groups of eight, washed, quickly frozen in dry ice, and stored at $-70^{\circ} \mathrm{C}$. Oocytes were microinjected in the nucleus according to Bozzoni et al. (1984). 


\section{Preparation of cell extracts}

Each group of embryos was homogenized still frozen in $100 \mu \mathrm{l}$ of a sterile solution containing $10 \mathrm{~mm}$ HEPES (pH 7.4), $100 \mathrm{~mm}$ $\mathrm{NaCl}, 1 \mathrm{~mm} \mathrm{MgCl}, 5 \mathrm{~mm}$ DTT, and $300 \mathrm{U} / \mathrm{ml}$ of RNase inhibitor (Boehringer). Half of the sample was rapidly placed in an Eppendorf tube containing $350 \mu \mathrm{l}$ of a solution containing 1 $\mathrm{mg} / \mathrm{ml}$ Proteinase $\mathrm{K}$ and $2 \%$ SDS for extraction of nucleic acid (Probst et al. 1979); the other half was acid-extracted for preparation of proteins (Pierandrei-Amaldi and Beccari 1980). When preparing polysomes, nuclei were pelleted at $2000 \mathrm{rpm}$ for 5 min and cytoplasmic fractions were separated on $15-50 \%$ sucrose gradients as already described (Pierandrei-Amaldi et al. 1985a). The fractions corresponding to polysomes and mRNP were pooled and precipitated with 3 volumes of ethanol.

\section{Extraction and analysis of DNA and RNA}

Nucleic acids from embryos, oocytes, and gradient fractions were extracted with proteinase $\mathrm{K} /$ phenol/chloroform according to Probst et al. (1979). An aliquot of total nucleic acid was used for DNA analysis by Southern blot either undigested or after digestion with BamHI. Poly $(A)^{+}$RNA was obtained by oligo(dT)-cellulose chromatography and was analyzed by Northern blotting. Filters were hybridized to ${ }^{32} \mathrm{P}$-labeled Ll and L14 cDNA single-stranded probes as previously described (Pierandrei-Amaldi et al. 1985a).

\section{S1 analysis}

SI nuclease mapping was carried out according to the procedure described by Bozzoni et al. (1984). The probe utilized is an 813 bp long XbaI-PvuII fragment that includes $633 \mathrm{bp}$ of the L1 gene extending from the $X b a \mathrm{I}$ site of intron 3 to the PstI site of exon 2, plus $180 \mathrm{bp}$ coming from the PstI-PvulI sequence of the pSP-65 plasmid in which the fragment has been cloned utilizing the $\mathrm{XbaI}$ and PstI sites in the polylinker region. The fragment was $5^{\prime}$-end-labeled at the $\mathrm{XbaI}$ terminus with polynucleotide kinase and annealed in $80 \%$ formamide, $0.4 \mathrm{M} \mathrm{NaCl}, 40 \mathrm{mM}$ MOPS (3- $N$-morpholine acid) $(\mathrm{pH} 6.7)$, and $1 \mathrm{~mm}$ EDTA together with total RNA. The annealing was allowed to proceed for $12 \mathrm{hr}$ at $50^{\circ} \mathrm{C}$. The $\mathrm{S} 1$ reaction was performed as already described (Bozzoni et al. 1982), and the products were analyzed on a $6 \%$ acrylamide-urea gel.

\section{Protein analysis}

Proteins were analyzed on two-dimensional acrylamide gels as previously described (Pierandrei-Amaldi et al. 1982).

\section{Densitometric analysis}

$\mathrm{X}$-ray films of Southern, Northern, and two-dimensional protein gels were quantitated by analysis with a LKB Ultroscan XL laser densitometer.

\section{Acknowledgments}

We wish to thank Dr. F. Amaldi for helpful discussion and critical reading of the manuscript. We are very grateful to Mrs. N. Campioni for skilled technical assistance. This research was partially supported by grants from Progetto Finalizzato Ingegneria Genetica e Basi Molecolari delle Malattie Ereditarie, C.N.R. and from Progetto Strategico Biologia Molecolare, C.N.R.

\section{References}

Andres, A.C., D.B. Muellener, and G.U. Ryffel. 1984. Persistence, methylation and expression of vitellogenin gene derivatives after injection into fertilized eggs of Xenopus laevis. Nucleic Acids Res. 12: 2283-2302.

Baum, E.Z. and W.M. Wormington. 1985. Coordinate expression of r-protein genes during Xenopus development. Dev. Biol. 111: 488-498.

Bendig, M.M. and J.G. Williams. 1984. Differential expression of the Xenopus laevis tadpole and adult $\beta$-globin genes when injected into fertilized Xenopus laevis eggs. Mol. Cell. Biol. 4: $567-570$.

Bozzoni, I., A. Tognoni, P. Pierandrei-Amaldi, E. Beccari, M. Buongiorno-Nardelli, and F. Amaldi. 1982. Isolation and structural analysis of ribosomal protein genes in Xenopus laevis. J. Mol. Biol. 161: 353-371.

Bozzoni, I., P. Fragapane, F. Annesi, P. Pierandrei-Amaldi, F. Amaldi, and E. Beccari. 1984. Expression of two Xenopus laevis r-protein genes in injected frog oocytes. A specific splicing block interferes with the L1 RNA maturation. $/$. Mol. Biol. 180: 987-1005.

Caffarelli, E., P. Fragapane, C. Gehring, and I. Bozzoni. 1987. The accumulation of mature RNA for the Xenopus laevis ribosomal protein $\mathrm{Ll}$ is controlled at the level of splicing and turnover of the precursor RNA. EMBO J. 6: 3493-3498.

Dabeva, M.D., M.A. Post-Beittenmiller, and J.R. Warner. 1986. Autogenous regulation of splicing of the transcript of a yeast ribosomal protein gene. Proc. Natl. Acad. Sci. 83: 58545857.

Etkin, L.D., B. Pearman, M. Roberts, and S.L. Bektesh. 1984. Replication, integration and expression of exogenous DNA injected into fertilized eggs of Xenopus laevis. Differentia tion 36: 194-202.

Geyer, P.K., O.K. Meyuhas, R.P. Perry, and L.F. Johnson. 1982. Regulation of ribosomal protein mRNA content and translation in growth stimulated mouse fibroblast. Mol. Cell. Biol. 2: 685-693.

Kay, M.A. and M. Jacobs-Lorena. 1985. Selective translational regulation of ribosomal protein gene expression during early development of Drosophila melanogaster. Mol. Cell. Biol. 5: $3583-3592$.

Krieg, P.A. and D.A. Melton. 1985. Developmental regulation of a gastrula-specific gene injected into fertilized Xenopus eggs. EMBO /. 4: 3463-3471.

Loreni, F., I. Ruberti, I. Bozzoni, P. Pierandrei-Amaldi, and F. Amaldi. 1985. Nucleotide sequence of the Ll ribosomal protein gene of Xenopus laevis: Remarkable sequence homology among introns. EMBO /. 4: 3483-3488.

Mohun, T.J., N. Garret, and J.B. Gurdon. 1986. Upstream sequences required for tissue-specific activation of the cardiac actin gene in Xenopus laevis embryos. EMBO /. 5: 31853193.

Nieuwkoop, P.D. and J. Faber. 1956. Normal table of Xenopus laevis (Daudin). North Holland, Amsterdam.

Nomura, N., R. Gourse, and G. Baughman. 1984. Regulation of the synthesis of ribosomes and of ribosomal components. Annu. Rev. Biochem. 53: 75-117.

Pierandrei-Amaldi, P. and E. Beccari. 1980. Messenger RNA for ribosomal proteins in Xenopus laevis oocytes. Eur. I. Biochem. 106: 603-611.

Pierandrei-Amaldi, P., N. Campioni, E. Beccari, I. Bozzoni, and F. Amaldi. 1982. Expression of ribosomal-protein genes in Xenopus laevis development. Cell 30: 163-171.

Pierandrei-Amaldi, P., E. Beccari, I. Bozzoni, and F. Amaldi. 1985a. Ribosomal protein production in normal and anu- 
cleolate Xenopus embryos: Regulation at the posttranscriptional and translational levels. Cell 42: 317-323.

Pierandrei-Amaldi, P., N. Campioni, P. Gallinari, E. Beccari, I. Bozzoni, and F. Amaldi. 1985b. Ribosomal protein synthesis is not autogenously regulated at the translational level in Xenopus laevis. Dev. Biol. 167: 281-289.

Pierandrei-Amaldi, P., F. Amaldi, I. Bozzoni, and P. Fragapane. 1987. Regulation of ribosomal protein genes during Xenopus development. ICN-UCLA Symp. Mol. Cell. Biol. 51: 267278.

Probst, E., A. Kressmann, and M.L. Birstiel. 1979. Expression of sea urchin histone genes in the oocyte of Xenopus laevis. $/$. Mol. Biol. 135: 709-732.

Rusconi, S. and W. Schaffner. 1981. Transformation of frog embryos with the rabbit $\beta$-globin gene. Proc. Natl. Acad. Sci. 78: 5051-5055.

Schmidt, T., P.S. Chen, and M. Pellegrini. 1985. The induction of ribosome biosynthesis in a non-mitotic secretory tissue. J. Biol. Chem. 260: 7645-7650.

Team, J.L. and M. Rosbash. 1983. Expression of a $\beta$-galactosidase gene containing the ribosomal protein 51 intron is sensitive to the rna 2 mutation of yeast. Proc. Natl. Acad. Sci. 80: 4403-4407.

Wilson, C., G.S. Cross, and H.R. Woodland. 1986. Tissue specific expression of actin genes injected into Xenopus embryos. Cell 47: 589-599. 


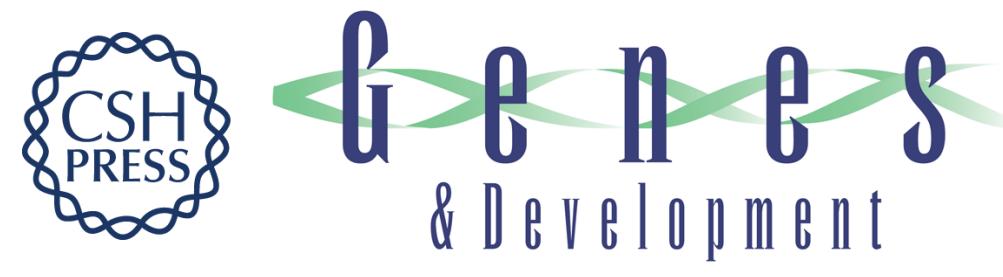

\section{Expression of the gene for ribosomal protein L1 in Xenopus embryos: alteration of gene dosage by microinjection.}

P Pierandrei-Amaldi, I Bozzoni and B Cardinali

Genes Dev. 1988, 2:

Access the most recent version at doi:10.1101/gad.2.1.23

References This article cites 24 articles, 7 of which can be accessed free at: http://genesdev.cshlp.org/content/2/1/23.full.html\#ref-list-1

License

Email Alerting

Receive free email alerts when new articles cite this article - sign up in the box at the top Service right corner of the article or click here.

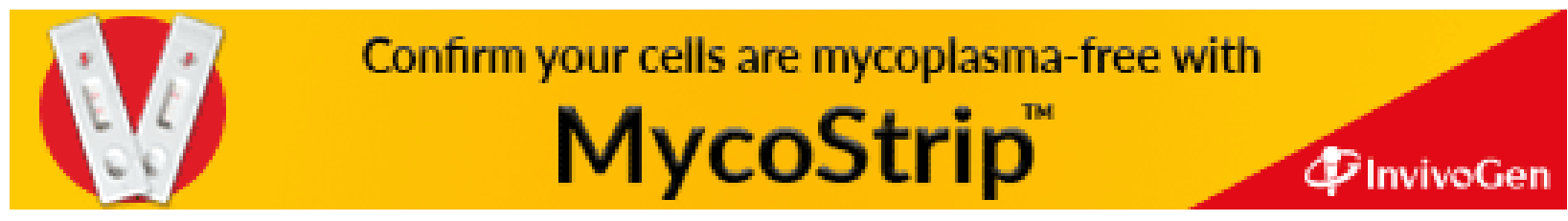

